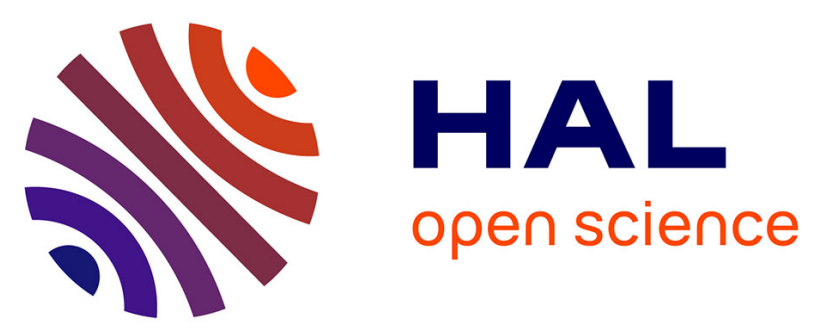

\title{
Mineralogy of the Nili Fossae region with OMEGA/Mars Express data: 1. Ancient impact melt in the Isidis Basin and implications for the transition from the Noachian to Hesperian
}

\author{
J.-F. Mustard, F. Poulet, J.-W. Head, N. Mangold, J.-P. Bibring, S.-M. \\ Pelkey, C. Fassett, Y. Langevin, G. Neukum
}

\section{To cite this version:}

J.-F. Mustard, F. Poulet, J.-W. Head, N. Mangold, J.-P. Bibring, et al.. Mineralogy of the Nili Fossae region with OMEGA/Mars Express data: 1. Ancient impact melt in the Isidis Basin and implications for the transition from the Noachian to Hesperian. Journal of Geophysical Research. Planets, 2007, 112, pp.e08s03. hal-00376823

\section{HAL Id: hal-00376823 \\ https://hal.science/hal-00376823}

Submitted on 22 Sep 2021

HAL is a multi-disciplinary open access archive for the deposit and dissemination of scientific research documents, whether they are published or not. The documents may come from teaching and research institutions in France or abroad, or from public or private research centers.
L'archive ouverte pluridisciplinaire HAL, est destinée au dépôt et à la diffusion de documents scientifiques de niveau recherche, publiés ou non, émanant des établissements d'enseignement et de recherche français ou étrangers, des laboratoires publics ou privés. 


\title{
Mineralogy of the Nili Fossae region with OMEGA/Mars Express data: 1. Ancient impact melt in the Isidis Basin and implications for the transition from the Noachian to Hesperian
}

\author{
J. F. Mustard, ${ }^{1}$ F. Poulet, ${ }^{2}$ J. W. Head, ${ }^{1}$ N. Mangold, ${ }^{3}$ J.-P. Bibring, ${ }^{2}$ S. M. Pelkey, ${ }^{1}$ \\ C. I. Fassett, ${ }^{1}$ Y. Langevin, ${ }^{2}$ and G. Neukum ${ }^{4}$ \\ Received 23 September 2006; revised 12 January 2007; accepted 3 April 2007; published 4 August 2007.
}

[1] The Nili Fossae region located on the northwestern quadrant of the Isidis Basin, Mars, displays superb exposures of bedrock outcrops that reveal mineralogy and composition of the crust. Previous work has shown that this region exhibits the largest exposures of olivine-dominated rock units on Mars. Visible-infrared imaging spectrometer data acquired by OMEGA were calibrated to surface reflectance and analyzed to determine surface mineralogy. The dominant minerals identified are iron-bearing mafic silicates (low- and high-calcium pyroxene, olivine) and water-bearing phyllosilicate (iron-rich smectite clay). The strength and position of mineral absorption features were used to produce mineral indicator maps for the dominant species, and the maps were integrated with high-resolution imaging from the THEMIS, MOC, and HRSC instruments, and MOLA topography. We show that olivine and phyllosilicate occur in spatially distinct outcrops; the olivine-bearing rock unit is a meters- to tens of meters-thick cap unit resting on phyllosilicate-bearing bedrock, and the phyllosilicate units predate the Isidis basinforming event. On the basis of superposition, crosscutting, and geomorphic relationships, we interpret the emplacement of the olivine-bearing units as having been

contemporaneous with the Isidis impact event. By analogy with the Orientale basin on the Moon, we propose that the olivine-bearing unit represents the surface exposure of the impact melt from the Isidis impact event. These results demonstrate that large regions of crust had been altered in the presence of water prior to the date of the Isidis basin-forming event in the Late Noachian $(\approx 3.96 \mathrm{Ga})$.

Citation: Mustard, J. F., F. Poulet, J. W. Head, N. Mangold, J.-P. Bibring, S. M. Pelkey, C. I. Fassett, Y. Langevin, and G. Neukum (2007), Mineralogy of the Nili Fossae region with OMEGA/Mars Express data: 1. Ancient impact melt in the Isidis Basin and implications for the transition from the Noachian to Hesperian, J. Geophys. Res., 112, E08S03, doi:10.1029/2006JE002834.

\section{Introduction}

[2] The Isidis Basin/Nili Fossae/Syrtis Major region has long attracted attention because of its interesting combination of impact basin formation into ancient cratered uplands (the Isidis Basin), volcanic modification of the western basin rim (Syrtis Major Planitia), tectonic deformation of the impact basin rim (Nili Fossae), and filling of the Isidis Basin (the Vastitas Borealis Formation) [e.g., Meyer and Grolier, 1977; Schaber, 1982; Grizzaffi and Schultz, 1989; Hiesinger and Head, 2004; Head et al., 2002; Mangold et al., 2007]. The region was mapped geologically at the scale

\footnotetext{
${ }^{1}$ Department of Geological Sciences, Brown University, Providence, Rhode Island, USA.

${ }^{2}$ Institut d'Astrophysique Spatiale, CNRS/Université Paris Sud, Orsay, France.

${ }^{3}$ Laboratoire IDES, UMR8148 CNRS and Université Paris-Sud, Orsay, France.

${ }^{4}$ Institut für Geologische Wissenschaften, Freie Universität Berlin, Berlin, Germany.

Copyright 2007 by the American Geophysical Union. 0148-0227/07/2006JE002834
}

of 1:15M [Greeley and Guest, 1987] and updated by Tanaka et al. [2005]. The stratigraphic units and sequence were interpreted as follows: Early Noachian: Isidis Basin formation, followed by Middle and Late Noachian emplacement of a series of plains units on the basin exterior, rim and interior, and faulting to form Nili Fossae; mid-Hesperian: Syrtis Major Planitia volcanic emplacement covers the western rim and basin margin; Amazonia: Isidis Planitia unit, similar to the Vastitas Borealis Formation, fills the basin floor in the Early Amazonian followed by emplacement of knobby and smooth plains that fringe the margin of the basin floor. The wide array of post-basin geomorphic units led to the general impression that primary Isidis Basin impact deposits had been highly modified and largely buried by eolian, volcanic, and fluvial deposits, and anhydrous weathering processes operating over the approximately 4 billion years since the formation of the Isidis impact basin.

[3] The advent of remote sensing instruments onboard Mars orbiting spacecraft led to interpretations of the mineralogy of this important region. Global Thermal Emission Spectrometer (TES) data (3 by $6 \mathrm{~km}$ spatial resolution) were interpreted to indicate the presence of both basalt and 
basaltic andesite in the region [Bandfield et al., 2000]. Hamilton et al. [2003] used TES data and supported an interpretation that the Nili Fossae region was volumetrically dominated by basalt, but had spectral components consistent with olivine-rich materials. Hoefen et al. [2003] assessed possible origins of the olivine-rich material including ultramafic or mafic units/shallow intrusions exposed by Isidis basin tectonics or post-Isidis basaltic volcanism and outlined a series of possible interpretations related to exposure of olivine-rich crustal material by (1) basin faulting, (2) extrusive volcanism, or (3) later erosion.

[4] More recently, Hamilton and Christensen [2005] used Thermal Emission Imaging System (THEMIS) data (100 m spatial resolution) to analyze the extensive exposures of olivine-rich bedrock in the Nili Fossae region. Most surfaces characterized by strong olivine signatures also showed higher nighttime temperatures than olivine-poor materials, suggesting more rock-rich surfaces. However some exceptions were observed, suggesting that the olivine-rich materials may be exposed in more than one form. Hamilton and Christensen [2005] used high-resolution imaging to show that the majority of the olivine-rich material occurred in the form of in-situ rock outcrops with features that suggested layering. By extension to high thermal inertia regions to the north of these outcrops that lacked spectral signatures of olivine presumably due to dust cover, they hypothesized that olivine-bearing lithologies cover an area significantly larger than previously suspected. Details of the olivine-rich area revealed by THEMIS and Mars Orbiter Camera (MOC), visible images (1-5 m spatial resolution) were interpreted by Hamilton and Christensen [2005] as in-place bedrock and sedimentary (dune) deposits superimposed on these bedrock units. The paucity of olivine enrichment west of $\sim 76.5 \mathrm{E}$ at high elevations, together with geomorphic data, suggested to Hamilton and Christensen [2005] that the high plateau was being eroded to exhume and expose the olivine-rich material and that the regional tilt of the slope and the apparently dipping bedding planes indicated that tectonic uplift had occurred.

[5] Hamilton and Christensen [2005] outline several igneous, sedimentary and metamorphic hypotheses for the origin of the olivine-enrichment. Among the candidate igneous origins were (1) olivine-rich basalt distinct from typical basalts on Mars, (2) olivine-rich xenoliths in basalt, (3) komatiite flows, (4) cumulate rocks, (5) intrusive sills, (6) layered igneous intrusions, and (7) ophiolite-like sequences. Hamilton and Christensen [2005] found little evidence to support metamorphic processes. On the basis of the large flood-basalt-like areal extent, volume of the unit, evidence for possible layering, and morphologic features interpreted to be volcanic flows, Hamilton and Christensen [2005] conclude that the evidence best supports olivine-rich basalts extruded subaerially as the source of the anomalies. On the basis of cross-cutting of the olivine-rich unit by major Nili Fossae fractures, the lack of olivine in these fractures, and the presence of olivine across the regional slope, Hamilton and Christensen [2005] argue that the olivine-rich unit was present at the time of the Isidis impact.

[6] Left unexamined are the specific relationships between the Isidis basin-forming event, its deposits and the olivine-rich units interpreted by Hamilton and Christensen [2005] to be of volcanic origin. Where and in what context might extensive flood-basalt like extrusive volcanic deposits remain near the surface subsequent to a major basin-forming event such as Isidis? Furthermore, phyllosilicates have been recently detected by OMEGA in this region [Bibring et al., 2005, 2006; Poulet et al., 2005]. How is the presence of minerals indicating strong aqueous alteration reconciled with the idea of a dry and cold Mars subsequent to the emplacement of the mafic units [Hoefen et al., 2003]? We examine these questions with new compositional and imaging data from the Mars Express mission. Specifically, with mineralogic mapping from the Observatoire pour la Minéralogie, l'Eau, les Glaces, et l'Activité (OMEGA 0.3$4.8 \mathrm{~km}$ spatial resolution) and imaging from High Resolution Stereo Camera (HRSC, 4-30 m spatial resolution) we provide new insight into the stratigraphic relationship between the olivine-rich and pre-Isidis lithologies. We then examine the correlation of the olivine-rich unit to the regional geology of the Isidis basin and assess the nature of impact basin geology, setting, and formation and evolution processes, in order to assess further the relationship to the olivine-rich unit. A companion paper by Mangold et al. [2007] examines in detail the nature of phyllosilicatebearing units, their stratigraphy and relationship to the igneous rock units, and implications for the processes and timing of aqueous alteration.

\section{Geological Setting of the Isidis Basin/Nili Fossae/Syrtis Major Region and Comparison to the Lunar Orientale Basin}

[7] The rim of the Isidis basin itself (Figure 1) is quite variable in topography and is most well defined along the southern margin (Libya Montes), under Syrtis Major, and along the northwest margin in the vicinity of Nili Fossae (see discussion by Hiesinger and Head [2004] and their Figure 21). Although the Isidis basin, together with Argyre and Hellas, lack the clear-cut multiple distinctive rings of the lunar Orientale basin [e.g., Wilhelms, 1973; Schultz and Frey, 1990], following Wilhelms [1973], define two rings, one at $1100 \mathrm{~km}$ diameter (the outer edge of Isidis Planitia) and one at $1900 \mathrm{~km}$ (the outer edge of Nili Fossae). The diameter ratio of the two rings is 1.73 , most similar to the lunar values where the outer ring at about $1900 \mathrm{~km}$ would most likely represent the equivalent of the basin rim (the Cordillera ring of Orientale) [e.g., Head, 1977]. Differences in the development and expression of individual basin rings occur even within the Orientale Basin [e.g., Head, 1974; Wilhelms, 1987] and can be caused by a variety of factors [see discussion in Schultz and Frey, 1990].

[8] New MOLA altimetry data provide high-resolution topographic information about the Isidis Basin and the Nili Fossae area. These data reveal that the outer rim of the basin (northwest of Nili Fossae) forms a high plateau covering hundreds of thousands of square kilometers, and lying substantially above the basin interior to the east and southeast. A large arcuate graben (westernmost Nili Fossae) forms the easternmost margin of the basin rim. Just to the east of this graben an arcuate plateau about $75 \mathrm{~km}$ wide and $600 \mathrm{~km}$ long lies on average a few hundreds of meters below the basin rim. Along the interior margin of the arcuate plateau occurs a steep $1.3 \mathrm{~km}$ scarp, and from the base of this scarp, the topography descends systematically 


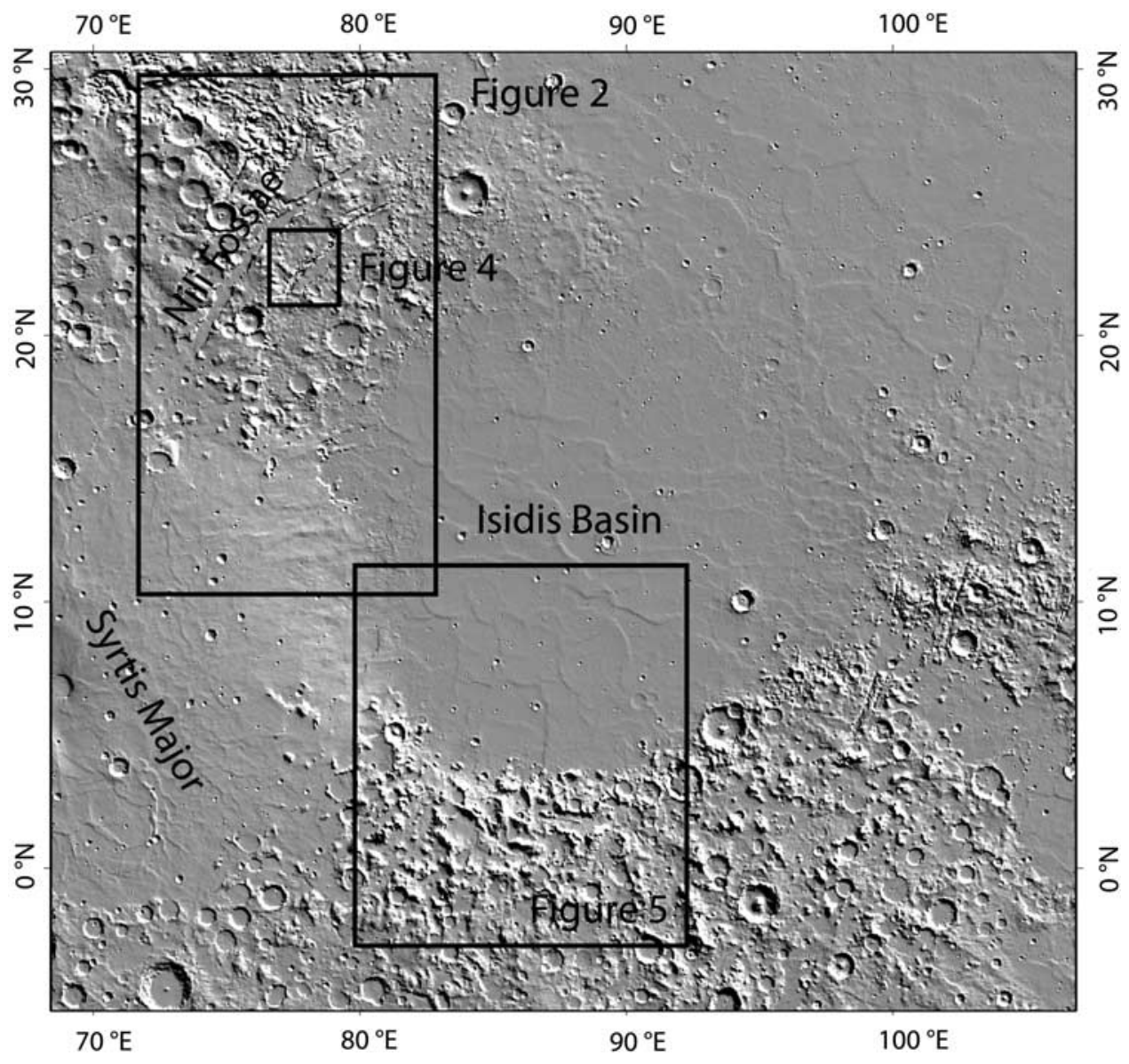

Figure 1. General location map for this study shown with MOLA shaded relief as the background. The locations for Figures 2, 4, and 5 are shown by the labeled boxes.

downslope toward the east, dropping about $2.5 \mathrm{~km}$ to the vicinity of the floor of the Isidis Planitia. These topographic relationships and the characteristics of more well-preserved multiringed basin deposits can help us to assess further the structure of Isidis Basin, the role of Nili Fossae, and the interpretation of the deposits in the region.

\section{OMEGA Data: Characteristics and Processing}

[9] New surface mineralogical information is available to assess the hypotheses for the formation of the Nili Fossae region from the OMEGA experiment on the Mars Express spacecraft. OMEGA has returned millions of reflectance spectra of the surface of Mars from which mineralogic assessments can be derived on the basis of electronic and vibrational absorptions [Bibring et al., 2004] complementing mineralogical interpretations from lattice-mode vibrations of the thermal infrared. Analysis of OMEGA data has revealed a diverse surface mineralogy from mafic silicates to hydrated sulfate and silicates minerals [Bibring et al., 2005; Mustard et al., 2005; Gendrin et al., 2005; Poulet et al., 2005] and these results complement and extend those obtained by previous instruments (e.g., TES, THEMIS).

[10] OMEGA consists of an infrared whisk-broom system coupled to a visible-near infrared push-broom system resulting in the measurement of surface radiance from 0.35-5.2 $\mu \mathrm{m}$ [Bibring et al., 2004, 2005]. We focus on the near-infrared reflectance measurements of the whiskbroom system $(0.96-2.6 \mu \mathrm{m})$ where observations of surface reflectance contain electronic and vibrational absorptions diagnostic of crust-forming and secondary minerals [Pieters and Englert, 1993; Clark, 1999]. All OMEGA data are systematically processed by applying known instrumental corrections, conversion of DN to radiance, division by the solar flux adjusted to the Mars distance to reduce the data to $\mathrm{I} / \mathrm{F}$, and lastly dividing by the cosine of the incidence angle relative to the aereoid [Bibring et al., 2005].

[11] The 0.96-2.6 $\mu \mathrm{m}$ wavelength region contains contributions to the measured radiance from atmospheric dust, water ice aerosols, $\mathrm{CO}_{2}$, and $\mathrm{H}_{2} \mathrm{O}$ vapor that need to be removed to analyze the surface composition. Following the work of Bibring et al. [2005] we perform an atmospheric correction assuming that the surface and atmospheric contributions are multiplicative, and that the atmospheric contribution follows a power law variation with altitude [Bibring et al., 1989]. This requires a model for the atmospheric transmission that is derived from a highresolution OMEGA observation crossing the summit of Olympus Mons. Assuming a constant surface contribution, the ratio of a spectrum from the base of Olympus Mons to one over the summit provides the atmospheric transmission spectrum at a power function of their difference in altitude. The atmospheric contribution to each spectrum is then removed by dividing the observation by the derived 
Table 1. Algorithms Used to Calculate Mineral Indicators From OMEGA Data

\begin{tabular}{|c|c|c|}
\hline Index & Method of Calculation $^{\mathrm{a}}$ & Notes \\
\hline Olivine & $\left(\frac{R 1695}{0.1 \times R 1050+0.1 \times R 1210+0.4 \times R 1330+0.4 \times R 1470}\right)-1$ & $\begin{array}{l}\text { olivine will be strongly positive pyroxene is } \\
\text { strongly }+ \text {; }\end{array}$ \\
\hline Low-calcium pyroxene & $\left(\frac{R 1330-R 1050}{R 1330+R 1050}\right) \times\left(\frac{R 1330-R 1815}{R 1330+R 1815}\right)$ & $\begin{array}{l}\text { favors low-calcium pyroxene pyroxene is } \\
\text { strongly }+;\end{array}$ \\
\hline High-calcium pyroxene & $\left(\frac{R 1470-R 1050}{R 1470+R 1050} \times \frac{R 1470-R 2067}{R 1470+R 2067}\right)$ & favors high-calcium pyroxene \\
\hline Phyllosilicate absorption near $2300 \mathrm{~nm}$ & $1-\left(\frac{C R 2869+C R 2314+C R 2327}{C R 2150+C R 2164+C R 2205}\right)$ & higher values for phyllosilicate minerals \\
\hline
\end{tabular}

${ }^{\mathrm{a}} \mathrm{R} \# \# \# \#$ is the reflectance measured at the given wavelength in nanometers. CR (continuum-removed) values are observed reflectance values divided by a straight line continuum defined as the slope as determined between $1.8-2.53 \mu \mathrm{m}$.

atmospheric spectrum, scaled by the strength of the $\mathrm{CO}_{2}$ atmospheric absorption measured in the observation.

[12] We have applied spectral parameters approaches [Mustard et al., 2004; Pelkey et al., 2007] that capture the principal mineralogic diversity. These are the same spectral parameters that will be applied to data returned by Compact Reconnaissance Imaging Spectrometer for Mars (CRISM) on the Mars Reconnaissance Orbiter. We consider the results from the parameter approach to be mineral indicators, but thorough verification of key occurrences lends confidence to the approach. Mineral indicator maps have been generated for olivine, low-calcium pyroxene, highcalcium pyroxene, and hydrated silicates with a sharp, narrow absorption near $2.3 \mu \mathrm{m}$. The formulas for the calculation of the parameters are given in Table 1. Maps summarizing the distributions of these mineral indicators are shown in Figure 2. These are the dominant mineral signatures observed for this area and in this wavelength region.

\section{Results: Mineralogy and Morphologic Associations}

[13] In the Nili Fossae region of Mars the spectral variance is dominated by the presence of Fe-bearing mafic minerals (i.e. olivine, pyroxene) and $\mathrm{H}_{2} \mathrm{O}$ and $\mathrm{OH}^{-}$-bearing phyllosilicates. In Figure 3 are shown OMEGA spectra from this region exhibiting these diverse spectral properties. Electronic absorptions due to Fe in silicate minerals were defined and characterized by Burns [1993] and Adams [1974] and updated by Cloutis and Gaffey [1991]. Lowcalcium pyroxene is identified on the basis of a strong absorption centered near $2 \mu \mathrm{m}$ and the increase in reflectance from $0.95-1.3 \mu \mathrm{m}$ representing the long-wavelength edge of the $1 \mu \mathrm{m}$ pyroxene band. Low-calcium pyroxene on Mars is readily identified by the distinct reflectance maximum near $1.3 \mu \mathrm{m}$ between the 1 and $2 \mu \mathrm{m}$ crystal field absorption bands. High-calcium pyroxene also exhibits crystal field absorption bands near 1 and $2 \mu \mathrm{m}$ but they are centered toward longer wavelengths resulting in a reflectance maximum near $1.6 \mu \mathrm{m}$. Olivine exhibits strong crystal field absorptions due to Fe between 0.8 and $1.5 \mu \mathrm{m}$ that broaden and deepen with increasing Fe content in the olivine. The olivine absorptions observed in these OMEGA data are particularly strong (30\%) and broad. This may be caused by olivine of high Fe content (e.g., fayalite) or large particle sizes. On the basis of the character of the absorptions it is not possible to distinguish between these options, though the relatively high albedo of the most concentrated olivine regions would favor the olivine present as very large grain sizes $(>1 \mathrm{~mm})$. The parameters designed to capture these mineralogic differences (Table 1) indicate relative enrichments in the minerals, and do not indicate or imply the presence of pure mineral concentrations. In other words a high value of low-calcium pyroxene indicates a relative enrichment in low-calcium pyroxene but that other minerals, such as high-calcium pyroxene, are usually present.

[14] Hydrated minerals on Mars recognized in reflectance spectroscopy occur as sulfates [Gendrin et al., 2005] and phyllosilicates [Poulet et al., 2005]. Assignment of absorption bands to crystal structure and mineral groups was recently reviewed by Clark [1999]. Minerals with water molecules in their crystal structure (e.g., gypsum, montmorillonite) exhibit absorptions near $1.9 \mu \mathrm{m}$ due to the combination of the $\mathrm{OH}$ stretch and $\mathrm{H}-\mathrm{O}-\mathrm{H}$ bend as well as an absorption near $1.4 \mu \mathrm{m}$ due to the first overtone of the $\mathrm{OH}$ stretch. Minerals with hydroxyls show the $1.4 \mu \mathrm{m}$ band as well as narrow absorptions between 2.0-2.6 $\mu \mathrm{m}$ which are typically combination overtones of $\mathrm{OH}$ stretch and metal$\mathrm{OH}$ bend. Sulfates identified on Mars show combination overtones near 2.2 (gypsum) and $2.4 \mu \mathrm{m}$ (gypsum, epsomite, polyhydrated sulfates). Phyllosilicates identified on Mars exhibit combination overtones near 2.2 (montmorillonite) and between 2.28-2.32 $\mu \mathrm{m}$ (Fe-rich smectite clays) [Poulet et al., 2005]. In the Nili Fossae region narrow absorptions between 2.28 and 2.32 are observed (Figure 3) consistent with phyllosilicates but not sulfates. The $1.9 \mu \mathrm{m}$ water band is often present in spectra showing the 2.28$2.32 \mu \mathrm{m}$ bands, though there are many examples where the $1.9 \mu \mathrm{m}$ water band is weak. Smectite clay minerals that have been dehydrated [Milliken and Mustard, 2005] or nonwater-bearing phyllosilicate minerals (e.g., chlorite) will have weak to absent $1.9 \mu \mathrm{m}$ water bands. The example OMEGA spectrum shown in Figure 3 shows very clear 1.4, 1.9 and $2.3 \mu \mathrm{m}$ absorptions and is consistent with nontronite (note that the laboratory spectrum of nontronite has a much larger $1.9 \mu \mathrm{m}$ band and a stronger drop in reflectance toward $2.5 \mu \mathrm{m}$ likely due to the high levels of hydration compared to the Martian observations). Other candidate minerals such as chlorite or serpentine have absorptions centered near $2.33 \mu \mathrm{m}$, a distinctly longer wavelength than nontronite. This difference in band position can be resolved with the spectral resolution of OMEGA, demonstrating that chlorite and serpentine are not present.

[15] Merging the results of mineral mapping with OMEGA data with high-resolution imaging of HRSC and THEMIS 

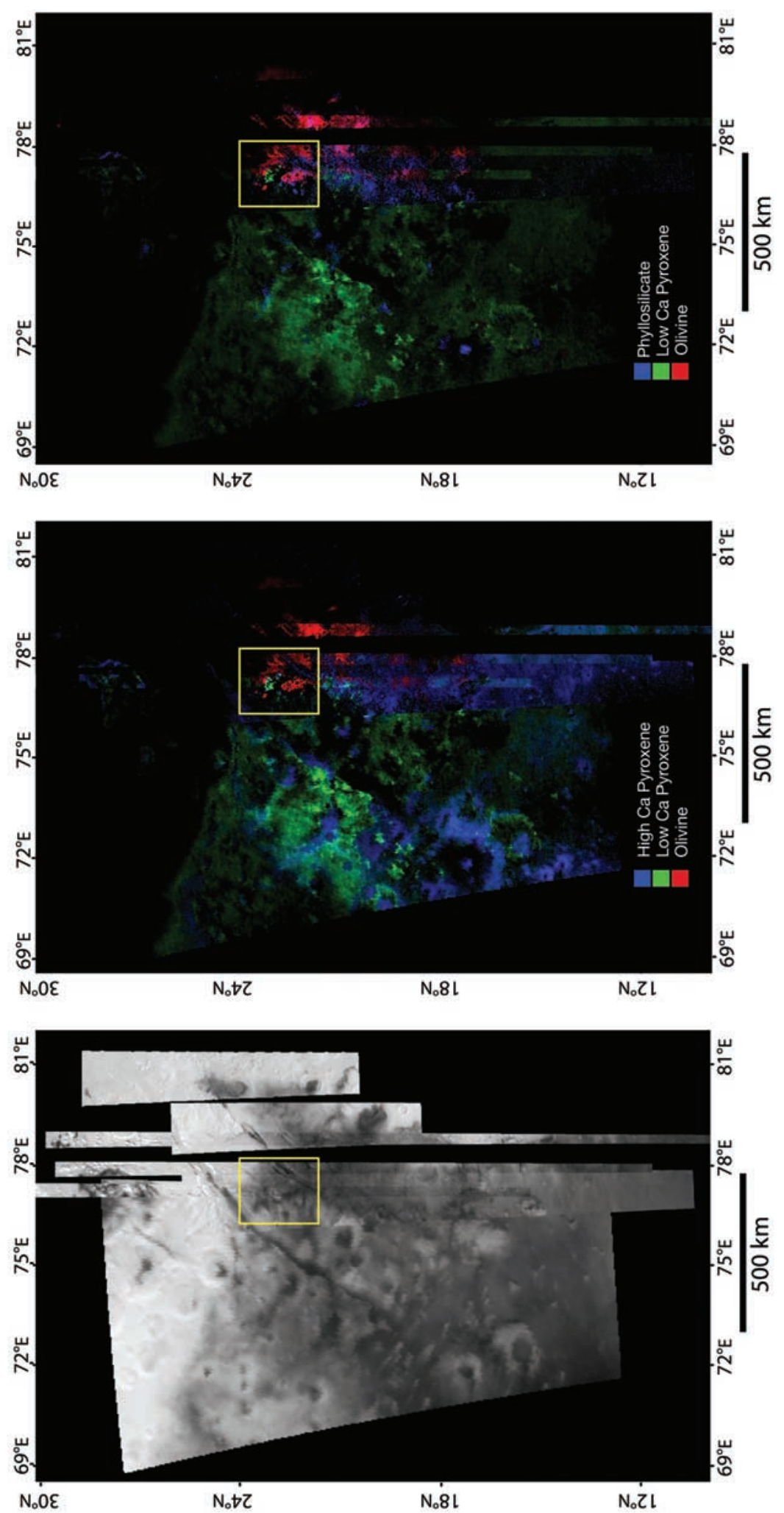

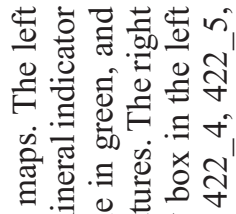

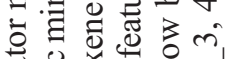

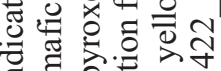

$\exists$ 르워

पु

के

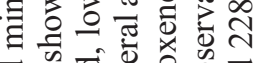

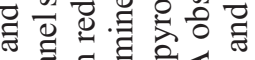

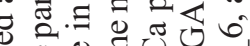

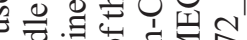

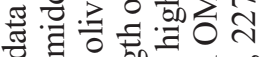

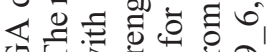

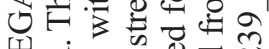

$\sum$ वंच

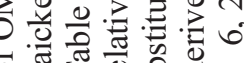

o

品: $\Xi$ के

एँ

o.류 0

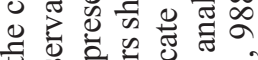

on

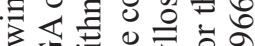

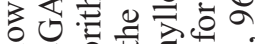

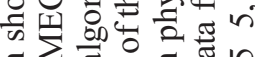

ธี ส

कू Ð

入.

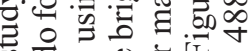

की

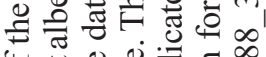

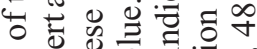

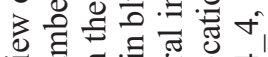

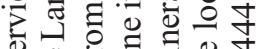

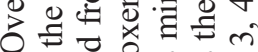

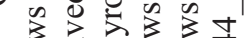

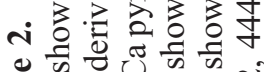

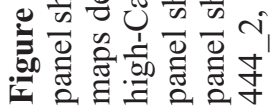



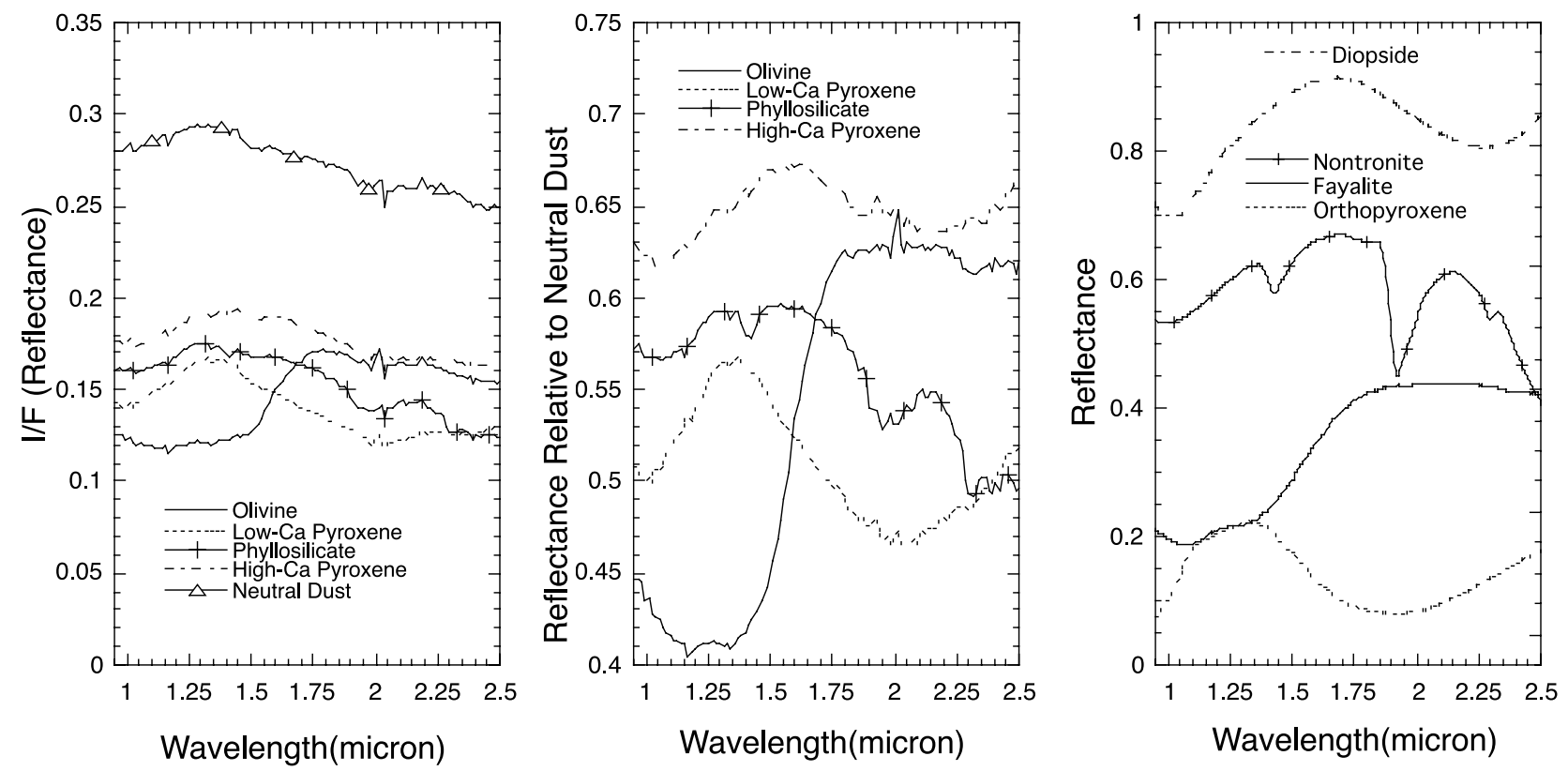

Figure 3. OMEGA reflectance spectra showing the four main spectral types in the Nili Fossae region extracted from observation 988 5 compared with laboratory spectral of minerals. In the left panel are shown the I/F (corrected for the incidence angle) for surfaces dominated by olivine, low-Ca pyroxene, phyllosilicate, and high-Ca pyroxene. A spectrum of typical bright regions (Neutral Dust) from the same area is also shown. In the middle panel are shown the same data as in the left panel but now normalized to the spectrum of Neutral Dust. Normalization removes residual instrumental and atmospheric features common to all observations. The right panel shows laboratory spectra from the RELAB spectral library of the minerals diopside (a high-Ca pyroxene), orthopyroxene (a low-Ca pyroxene), fayalite (high-Fe olivine), and nontronite (an Fe smectite clay). The short-dash line show the $1.9 \mu \mathrm{m}$ position and the longdash line shows the $2.3 \mu \mathrm{m}$ position to aid in identifying the mineral features.

(Figures 2 and 4) allows us to identify the composition of specific outcrops and thus interpret geomorphic landforms in terms of composition. On a regional level, the distribution of olivine (Figure 4) is completely consistent with the maps of olivine generated through TES [Hoefen et al., 2003] and THEMIS [Hamilton and Christensen, 2005] data. Olivine lies largely within the region $76.6^{\circ}-79^{\circ} \mathrm{E}$ and $20.5^{\circ}-$ $23.5^{\circ} \mathrm{N}$ across an elevation range of 1000 to $-2000 \mathrm{~m}$. In the main body of the olivine deposit, the terrain slopes from the northwest to the southeast and is intersected by several troughs of the Nili Fossae complex (Figure 1). Hamilton and Christensen [2005] noted that the morphology of the region exhibits evidence for erosion and the olivine-rich region consists of bedrock exposures (as evidenced by high nighttime temperatures in THEMIS thermal data) and mobile dune material.

[16] There is an additional region of enhanced olivine concentration near $4^{\circ} \mathrm{N}$ and $85^{\circ} \mathrm{E}$ along the southwestern edge of the Isidis basin, and in the same region that Hoefen et al. [2003] mapped olivine (Figure 5). These olivine-rich outcrops lie along the southern margin of the Isidis Basin and in THEMIS VIS images appear to be embayed by the Hersperian and younger deposits on the floor of Isidis. Approximately $50 \mathrm{~km}$ to north of the olivine deposits is an $18 \mathrm{~km}$ diameter impact crater. Analysis of THEMIS data suggests that olivine is exposed in the ejecta deposits, wall rock, and slump blocks adjacent to the crater floor [Tornabene et al., 2006]. Additional olivine occurrences are indicated associated with a $10 \mathrm{~km}$ diameter crater approxi- mately $80 \mathrm{~km} \mathrm{NW}$ of the $18 \mathrm{~km}$ diameter crater [Tornabene et al., 2006]. These occurrences may indicate a regional olivine-rich deposit beneath the cover in the Isidis basin.

[17] An important region that preserves apparent superposition and geologic context relationships in the Nili Fossae region is shown in Figure 6. Olivine-rich outcrops are spatially distinct from phyllosilicate-rich outcrops. The olivine-dominated surfaces are associated with a distinctive morphology (Figure 6a) of dark material with a pitted surface and small circular structures interpreted to be impact craters. While the apparent strength of the olivine spectral signature is weaker than neighboring regions over these surfaces, examination of OMEGA spectra show that olivine is the only mineral signature identified. Rock surfaces typically have weaker mineral absorption features than their particulate equivalents due to less multiple scattering and/or the presence of coatings and alteration masking the interior. Where the olivine-bearing unit is degraded (Figures 4 and 6) or where the surfaces are covered in mobile materials [Hamilton and Christensen, 2005] the olivine absorptions strengthen. We interpret this to indicate increased multiple scattering or removal of coatings. Some of the strongest olivine absorptions are observed over surfaces exhibiting dunes or accumulations of particulate material (Figure 4). The olivine-bearing unit is observed on the plateaus adjacent to the numerous fossae in the region as a coherent upper unit but there are no olivine-bearing outcrops observed along the walls or on the floors of the fossae as also noted by Hamilton and Christensen [2005]. Olivine signa- 

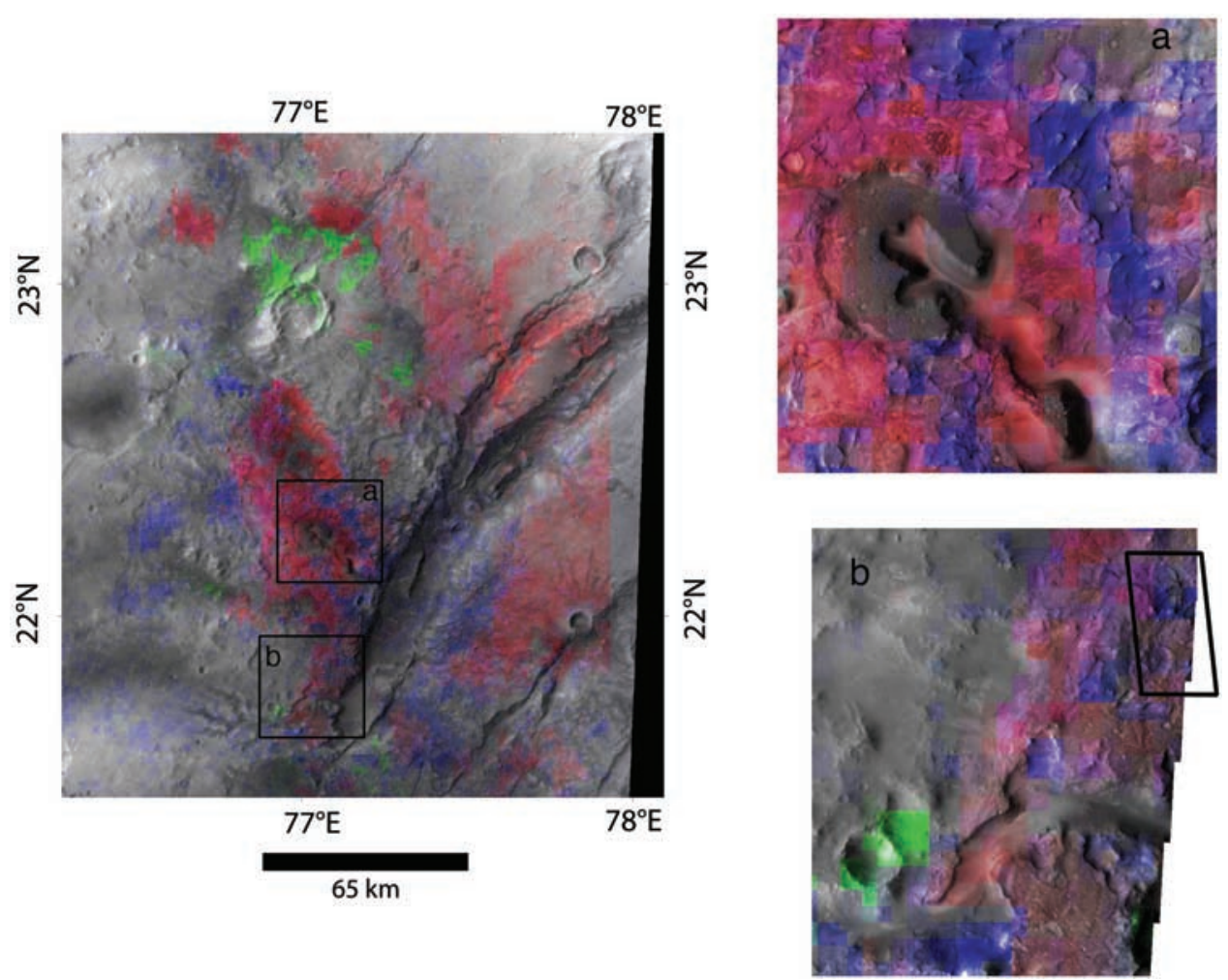

Figure 4. Detailed relationships between mineral indicators from OMEGA and morphology from HRSC and THEMIS data. The left image shows OMEGA mineral indicators with red, olivine; green, low-Ca pyroxene; and blue, phyllosilicate merged with HRSC imaging data. The brighter the color in this map, the stronger the mineral absorption band. The two insets, a and b, show further details of the relationships with the mineral indicators merged with THEMIS visible images $(20 \mathrm{~m} / \mathrm{pixel})$. The THEMIS images used are V02007010 and V09921011. In inset b the black box shows the location of Figure 6.

tures observed on the floors of the fossae are associated with mobile materials. On the basis of these observations, we interpret this competent rock unit as a meters-thick, olivinedominated cap unit.

[18] The nature of phyllosilicate-bearing rocks is discussed in detail by Mangold et al. [2007], but relevant aspects of these deposits are described here. The phyllosilicate-bearing surfaces are expressed as a recessive unit that rests beneath the olivine-dominated cap unit and exhibits distinctive knobs and ridges (Figures 4 and 6). The ridges are typically linear and of broadly similar width and apparent height. Where well exposed (Figure 6) they exhibit a range of parallel, branching and partly en echelon, long and short ridges. In some areas the ridges form a lattice-like network. Some ridges terminate against the cap unit and no expression of these ridges can be observed in the overlying unit. Head and Mustard [2006] describe a similar type of ridge morphology beneath a competent cap unit on the floors of craters in Nilosyrtis $\left(28.25^{\circ} \mathrm{N} 73.25^{\circ} \mathrm{E}\right)$ that they interpret to be breccia dikes formed during the impact process. The phyllosilicate-rich surfaces are also observed along the walls of the fossae and in remnant knobs within the fossae (Figure 4).

[19] Mangold et al. [2007] describe the broad occurrences of phyllosilicates in the region of Nili Fossae and north of Syrtis Major. They note the association of phyllosilicaterich surfaces with Noachian-aged outcrops and in the ejecta and walls of craters formed in these same-aged materials. A key conclusion is that a broad area of phyllosilicate alteration exists that is Noachian in age. We interpret the association of altered lithologies beneath the olivine-rich cap rock to indicate that the alteration occurred prior to the emplacement of the cap unit. The presence of a network of ridges interpreted to be impact breccia dikes in the phyllosilicate unit suggests that the alteration was present at the time of the formation of these dikes, or contemporaneous with dike emplacement. The lack of alteration of olivine across most of the olivine-dominated outcrops further demonstrates that active alteration processes had largely ceased by the time of the emplacement of the cap unit. As discussed by Mangold et al. [2007] however, there are some regions that can be interpreted as altered olivine-bearing units indicating that some local alteration continued after the emplacement of the cap unit. Nevertheless, the vast majority of olivine and phyllosilicate occurrences are in spatially distinct outcrops (Figures 4 and 6) indicating that this was not a widespread occurrence.

[20] To the south and west of these outcrops lies a relatively smooth unit that embays both the olivine-rich cap rock and the knobby phyllosilicate materials. The spectral signature of this material is dominated by the 1 and $2 \mu \mathrm{m}$ absorptions of pyroxene and is best modeled by a mixture of low- and high-calcium pyroxene but dominated by high-calcium pyroxene. This can be seen in as the 


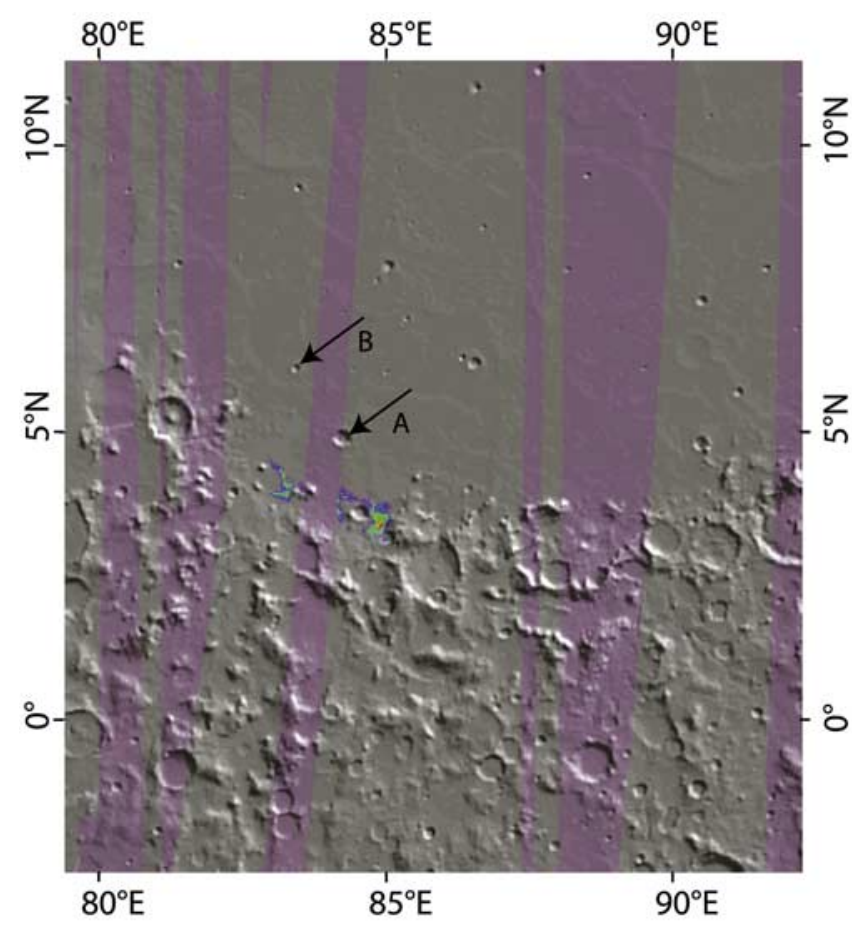

Figure 5. Olivine absorption band strength merged with MOLA shaded relief on the southern edge of the Isidis basin. Red indicates the highest mineral absorption strength, and blue indicates the lowest. The purple color indicates where no OMEGA data exist. The arrows point to craters that exhibit olivine in their ejecta as determined by THEMIS observations [Tornabene et al., 2006], where A refers to the $18 \mathrm{~km}$ diameter crater and $\mathrm{B}$ refers to the $10 \mathrm{~km}$ diameter crater.

smooth, grey, uncolored surfaces in the northwest portion of Figure $4 \mathrm{~b}$ and continuing into the channel to the south and east (it is not colored in this figure because the signature of high-calcium pyroxene is not mapped). This is the typical spectral signature of the volcanic surfaces of Syrtis Major and is interpreted as basalt [Mustard and Sunshine, 1995; Mustard et al., 1997].

[21] Surfaces dominated by low-calcium pyroxene are observed in isolated regions typically associated with the rims, walls, and ejecta of impact craters. This spectral signature is similar to that identified by Mustard et al. [2005] in the Noachian terrain north of Syrtis Major. Lowcalcium pyroxene-rich outcrops are common in this region and may be interpreted to indicate that the Noachian-aged crust throughout this area is enriched in low-calcium pyroxene. Thus the association of low-calcium pyroxene with the impact craters indicates excavation and exposure of Noachian basement. There does not appear to be any consistent stratigraphic relationship between unaltered Noachian crust, indicated by the presence of low-calcium pyroxene outcrops, and altered Noachian crust, indicated by the presence of phyllosilicates. Phyllosilicate-rich outcrops are observed directly at the surface (e.g., Figures 2 and 4) as well as in crater ejecta [Mangold et al., 2007], while the same observations are true of low-calcium pyroxene-rich outcrops [Mustard et al., 2005] (Figure 4). On the basis of these data there does not appear to be a simple stratigraphy of phyllosilicate-rich rocks overlying a lowcalcium pyroxene-enriched basement.

\section{Orientale Basin}

[22] The mineralogic results from OMEGA combined with morphologic data from imaging lead us to conclude that the olivine-rich materials in the Isidis Basin-Nili Fossae region are contained in a meters- to tens of meters-thick rock unit that rests on older crust, and both the olivine unit and older crust are of Noachian age. In many areas the crust upon which the olivine unit rests has been extensively altered as indicated by the presence of phyllosilicate minerals and this alteration occurred prior to the emplacement of the olivine-bearing rock unit. In evaluating a number of hypotheses to explain the occurrence of olivine in this region, Hoefen et al. [2003] and Hamilton and Christensen [2005] propose that mafic volcanic flows prior to the emplacement of Isidis Basin best explain the observations. Left unexamined is the possible role of the Isidis impact itself as a source for these compositions. Below we examine the hypothesis that the olivine-rich rocks are in fact impact melt from the Isidis basin-forming event by drawing comparisons to the Orientale Basin, one of the most wellpreserved impact basins in the Solar System.

[23] The Orientale Basin is a $930 \mathrm{~km}$ diameter impact basin in the western front side of the Moon (Figure 7). Three major structural ring complexes, from outside in, have been defined on the basis of topographica mountain ranges: Cordillera, Outer Rook and Inner Rook. The Outer Rook Mountains are interpreted as the closest approximation to the transient cavity rim while the Inner Rook interpreted as the equivalent to the central peak rings of smaller basins. The Cordillera is interpreted as the basin topographic rim, equivalent to the outer rim crest of smaller craters and basins, and thought to be formed by wall collapse of the transient cavity, and slumping and transient crater enlargement [Head, 1974; Howard et al., 1974; McCauley, 1977; Spudis et al., 1984; Head et al., 1993; Pieters et al., 1993]. Lying inside the Inner Rook ring is the inner depression, caused by subsidence and thermal contraction, and now filled with post-impact volcanic flows [Bratt et al., 1985].

[24] Three facies associated with the Orientale Basin are recognized; the Hevelius, Montes Rook, and Maunder formations. The Hevelius Formation consists of radially textured deposits and large crater chains modifying and "blanketing" underlying material. It lies outside the outer Cordillera ring and is interpreted as basin ejecta and secondary crater chains. The Montes Rook Formation, first called the domical facies by Head [1974], consists of domes 5-20 km in diameter and lies between the Outer Rook and the Cordillera rings. The region between these rings is interpreted by Head [1974] to be a huge "megaterrace" in contrast to the multiple small terraces seen in smaller craters. The texture is interpreted to be formed due to the slumping of the just-deposited ejecta off the uplifted rim and down into the megaterrace as the listric fault forming the megaterrace rotates into the basin.

[25] One of the characteristics of the impact cratering process is the production of impact melt lenses, sheets and dikes [e.g., Dressler and Reimold, 2001], with melt sheet 

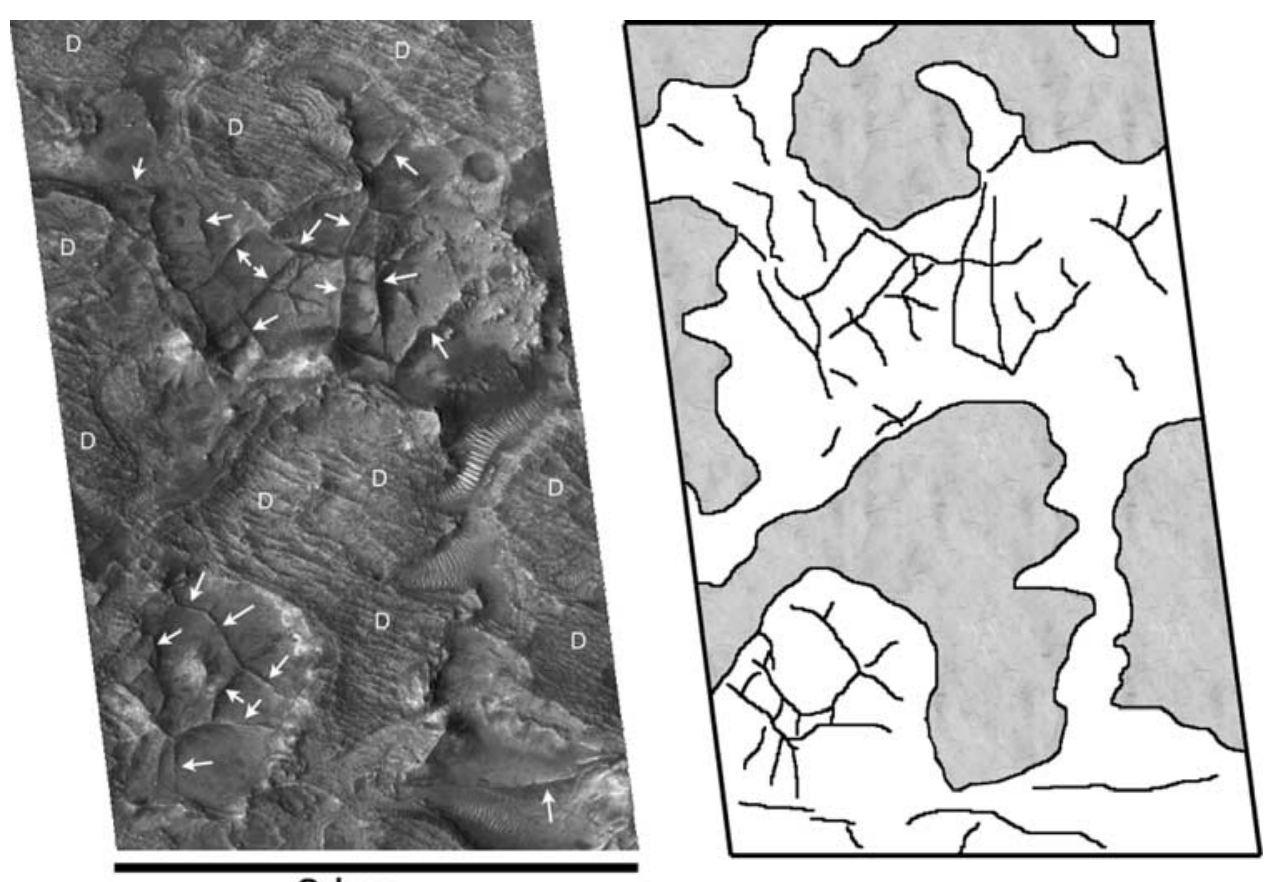

$3 \mathrm{~km}$

Figure 6. Details of relationships between olivine-bearing unit and phyllosilicate units in the Nili Fossae region. The image on the left is a subset of MOC image M0500782, and on the right is a sketch map of the main morphologic units observed in the image subset. In the image, the letter " $D$ " indicates the degraded surface of the olivine-bearing unit. The white arrows point to linear, intersecting ridges in the recessive phyllosilicate-bearing unit.
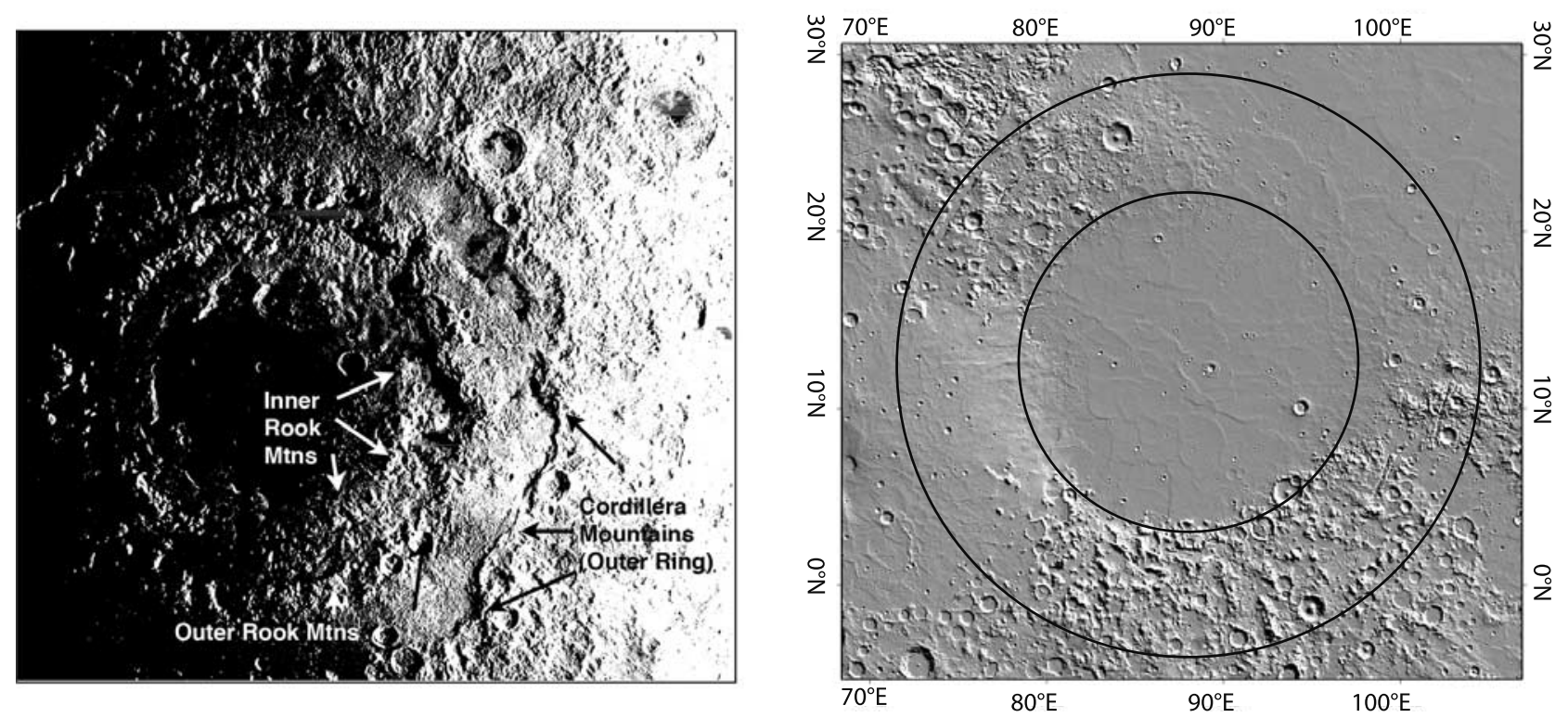

Figure 7. The left image shows a low sun angle image of Orientale taken by the camera on the Lunar Orbiter IV mission showing the location of the Inner Rook Mountains (inner ring), Outer Rook Mountains, and the Cordillera Mountains (outer ring). The diameter of the outer ring (Cordillera Mountains) is $930 \mathrm{~km}$. The right image shows MOLA shaded relief of the Isidis Basin with the location of the inner and outer rings of the Isidis from Schultz and Frey [1990]. The diameter of the outer ring is $1900 \mathrm{~km}$, and the inner ring is $1100 \mathrm{~km}$. 
a

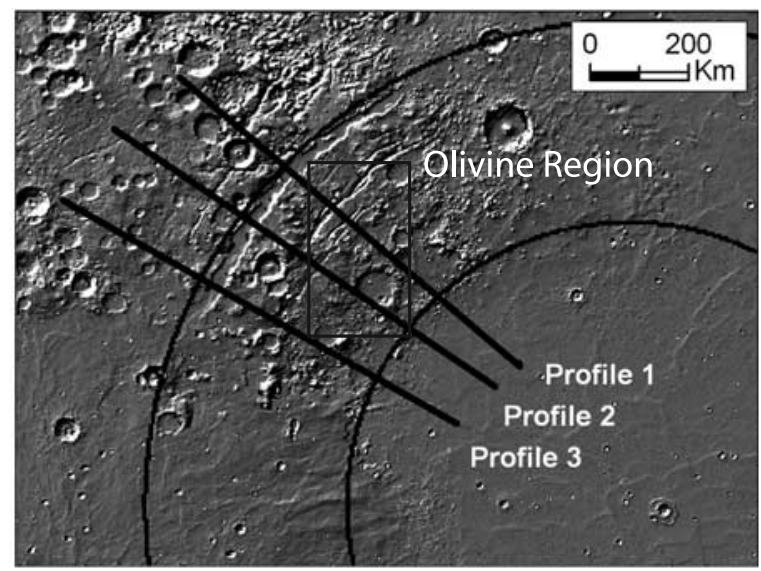

b
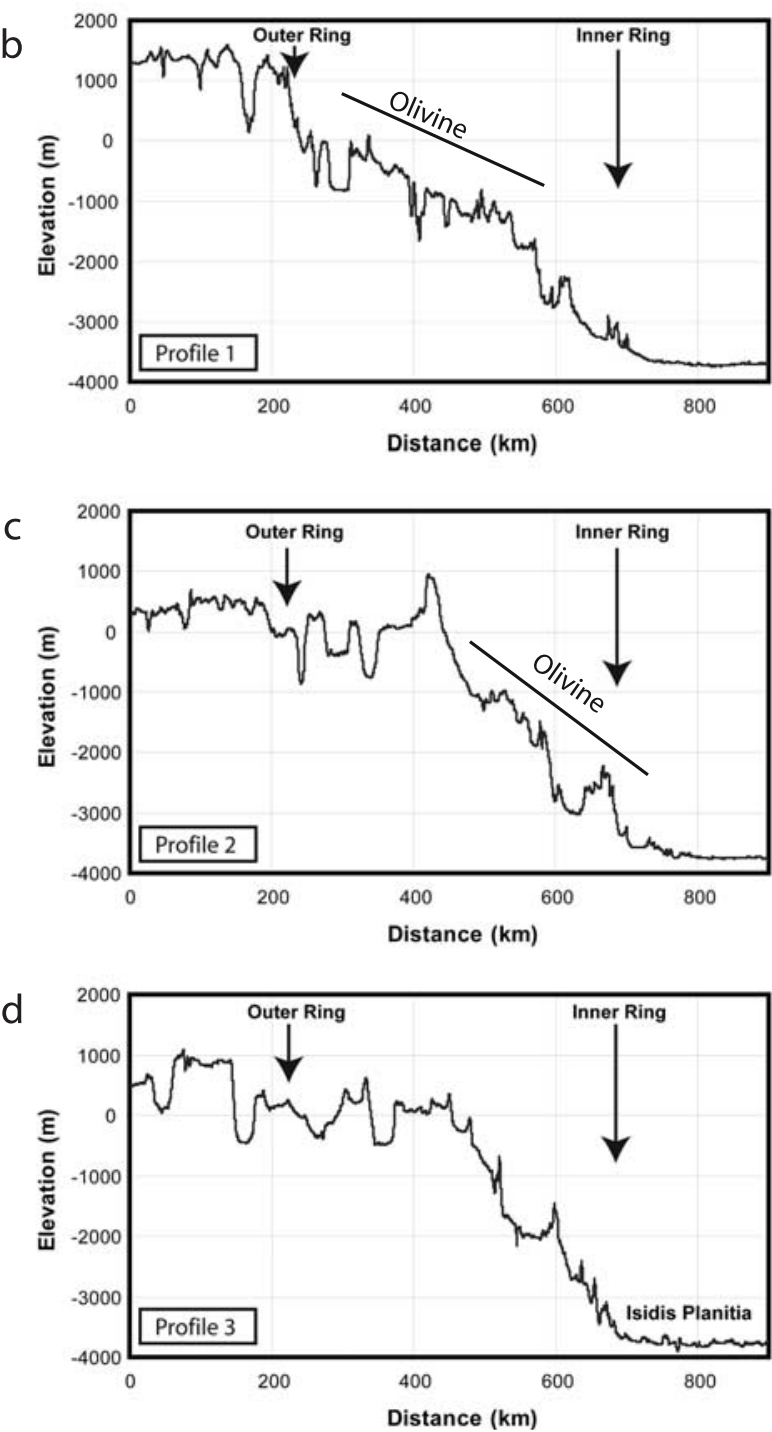

Figure 8. Altimetric profiles radial to the Isidis Basin and across the basin rim. (a) Shaded relief map (MOLA) showing the location of the profiles, and the basin rings at 1100 and 1900 diameter (see also Figure 7). (b) Altimetric profile 1. (c) Altimetric profile 2. (d) Altimetric profile 3. Vertical exaggeration on all profiles is $85 \mathrm{X}$. Olivine anomalies occur between the two rings (see Figures 2 and 7) and are labeled. occurrences ranging from small craters (the $3.8 \mathrm{~km}$ diameter Brent crater [Grieve, 1978]) to larger craters, such as the $100 \mathrm{~km}$ Popigai structure [Masaitis, 1994], the Manicouagan impact structure [Simonds et al., 1978], and the Igneous Complex at the Sudbury multiringed basin [Grieve and Stoffler, 1991]. These impact melt sheets range in thickness up to many hundreds of meters, are generally homogeneous in chemistry although they can be internally differentiated and layered, and are accompanied by networks of breccia and impact melt dikes injected into the substrate [e.g., Dressler and Reimold, 2001]. Likewise the degree of crystallinity varies depending on the rate of cooling and abundance of clasts. Grieve and Cintala [1992] have made the case that impact melt volume and crater dimensions scale at different rates, with large impact basins characterized by huge volumes of melt. The Maunder Formation (or corrugated facies of Head [1974]), consists of a randomly fractured and fissured layer of material draped over underlying terrain, which is exposed from beneath this layer as domes and massifs. The texture is very similar to the cracked and fissured floors of younger fresh impact craters such as Tycho and Copernicus and is interpreted to be impact melt draped over the transient cavity interior that rapidly cooled and cracked as the basin assumed its final configuration following transient cavity collapse. Smoother, light plains portions of the deposit in the basin interior are interpreted to be very fluid impact melt with less entrained debris [e.g., Head et al., 1993]. Small concentric graben observed in the basin interior along the northeast margins within the Outer Rook Mountains are interpreted to be due to post-basin loading and flexure largely related to mare fill [Solomon and Head, 1979, 1980]. Mare deposits formed from much younger basaltic lava flows characterize the interior of the basin in the inner depression (Mare Orientale) and occur as small patches along the basin rings to the NE (Lacus Veris and Autumni).

\section{Comparisons to the Isidis Basin}

[26] Using Orientale as an example of a well-preserved impact basin, we now compare Orientale to the Isidis basin impact structure and deposits. We interpret the Cordillera ring equivalent as most likely associated with the Isidis ring at $1900 \mathrm{~km}$ diameter [Schultz and Frey, 1990]. This is the most prominent ring and intersects the highest elevation in the northwest quadrant of the Isidis basin (Figure 8). This assignment is supported by the presence of subdued radial troughs, interpreted to be degraded remnants of radial crater chains, just outside (i.e., northwest) of the large Nili Fossae graben (Figures 7 and 8). Absent among the Isidis deposits and structures is the equivalent to the domical facies lying between the Cordillera and Outer Rook ring in Orientale. This portion of Isidis is more similar to the western margin of Orientale where the megaterrace is very poorly developed and a plateau-like area is observed instead. The arcuate plateau-like region along the NW Isidis margin is interpreted to be a section of the rim that faulted (outer Nili Fossae) but did not collapse into the basin.

[27] The Outer Rook Mountains, the closest approximation of the transient rim crest location in the Orientale basin [Head, 1974], is most analogous to the inner part of the arcuate terrace where the topography descends rapidly to the 

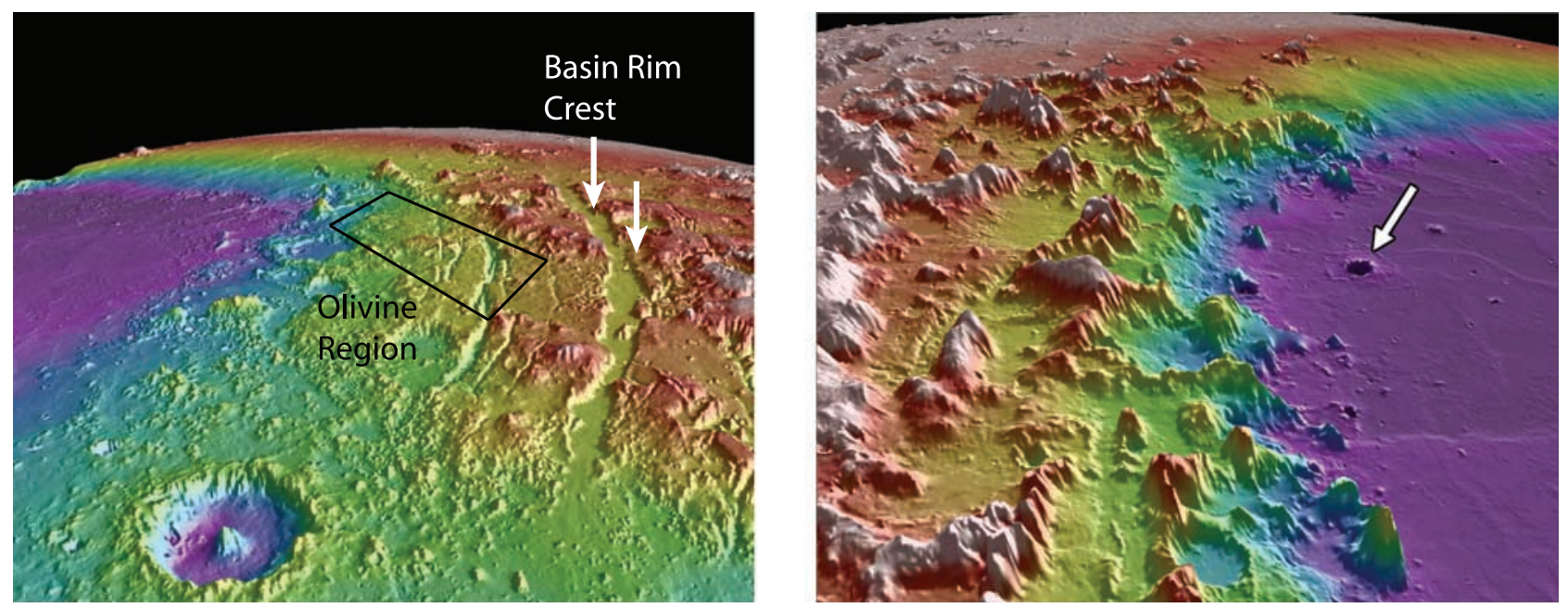

Figure 9. Perspective views of the Isidis basin rings (see also Figures 7 and 8) and the olivine anomaly localities. MOLA gradient maps with color-coded topography (purple is low; white is high) viewed perspectively. (a) Looking south along the northwestern part of the Isidis Basin rim. The crater Peridier is in the foreground, and the slumped and terraced basin interior deposits downdropped by graben are seen. The olivine anomaly area is in the central part of the image. Note the smoothness of the Syrtis Major Planitia lava flows in the background. (b) Looking west along the southern part of the Isidis Basin rim. Linear massifs mark parts of the basin interior structure. The smooth Syrtis Major Planitia lava flows are in the background. The arrow points to an $18 \mathrm{~km}$ crater, which has apparently excavated olivine material from below the Isidis Basin fill [e.g., Tornabene et al., 2006]. Additional olivine anomalies occur in the mountains at the edge of the basin, just to the south of the crater.

southeast (Figures 8 and 9) as it does in the Orientale basin. The Inner Rook Mountains are most closely analogous to a series of isolated massifs in the Isidis Basin that form a weakly defined ring near the $1100 \mathrm{~km}$ diameter ring (Figure 9b). The origin of these isolated peaks has always been an enigma, but the peak-ring interpretation seems very plausible when compared to Orientale [Head, 1974; McCauley, 1977]. The Inner Depression is the area that steps down topographically from the region of the peak ring (Figure 9), and the interior of the basin is largely filled with Hesperian ridged plains and the Vastitas Borealis Formation [Greeley and Guest, 1987; Ivanov and Head, 2003; Tanaka et al., 2005].

[28] The Maunder Formation, lying between the Inner and Outer Rook Mountains is interpreted to be the impact melt breccia from the Orientale basin-forming event. The analogous position in the Isidis basin occurs between the ring of isolated peaks and the sharp drop in topography from the elevated plateau in the northwest quadrant of the Isidis basin (Figure 8). It is in this region that the most abundant olivine deposits are observed with TES, THEMIS, and OMEGA data. The Maunder Formation drapes preexisting topography and has a fissured/pitted morphologic appearance. The texture of the olivine-bearing cap unit is different than that observed for the Maunder Formation, principally lacking the fissured appearance. Yet, the cap unit exhibits a pitted appearance, drapes preexisting topography and occurs at a range of elevations (from -400 to $-3100 \mathrm{~m}$ ).

\section{Interpretation of the Northwestern Isidis Basin/Nili Fossae Region}

[29] Drawing on these comparisons with the Orientale Basin, we propose an alternative model for the olivine-rich deposits in the Nili Fossae region that is coupled to the Isidis impact event. Exterior to the Isidis basin rim, the ejecta deposit is emplaced as strings of large secondaries and continuous ejecta (largely derived from the upper part of the crustal column) and creating the large-scale textured morphology radial to the basin. Vast quantities of impact melt are also produced [Grieve and Cintala, 1992], generally from the region of peak shock stress (with the lower part of the column being relatively more important) and the melt lines the cavity prior to cavity collapse. Estimates of the current crustal thickness beneath the Isidis Basin are on the order of 5-10 km [Neumann et al., 2004], among the thinnest regions of crust on the planet. Thus the Isidis Basin impact event likely penetrated many tens of $\mathrm{km}$ into the mafic lower crust or upper mantle of Mars, tapping olivinerich mafic and ultramafic rocks [McSween et al., 2003; Elkins-Tanton et al., 2005]. The amount of melt produced would depend on whether the impactor was a comet or asteroid, where comets produce more melt due to their greater velocity on impact [Pope et al., 2006]. Regardless, the amount of melt produced is prodigious, and on the order of several hundreds of meters of pure melt would have lined the transient crater cavity. The nature of the cratering process is likely to have mixed large quantities of unmelted rock to form impact melt breccias and/or suevites farther from the center of the basin.

[30] If the source of the olivine-rich rocks is impact melt, there is an expectation to find olivine occurrences on the southern and eastern rim of the Isidis Basin. A small occurrence of olivine is observed along the southern rim, seen in thermal emission and reflectance spectroscopic data [e.g., Hoefen et al., 2003; Tornabene et al., 2006] in the location expected for impact melt. The lack of olivine 
elsewhere may be explained by the presence of obscuring cover of dust, rock coatings, or alteration rinds or due to heterogeneity of impact melt composition.

[31] During the short-term modification stage, the transient cavity collapses and as the basin reaches topographic equilibrium, the impact melt flows into lows in the collapsed transient crater interior and cools rapidly [Grieve et al., 1977], lining the floor but also distributed over a range of elevations. Hummocks of crater floor material and faulted bedrock blocks protrude through the impact melt sheet, exposing underlying nonmelt material. Following the completion of the event, the basin undergoes a short-term evolution to thermal equilibrium (enhancing the formation of the inner depression due to thermal contraction [Bratt et al., 1985]), and begins to fill with other deposits (lava flooding, fluvial, eolian, etc.). Loading and flexure can cause additional smaller concentric graben, usually within the transient cavity [e.g., Comer et al., 1985; Wichman and Schultz, 1989]. In this scenario, the olivine-rich areas are the impact melt-breccia deposits and the phyllosilicate-rich areas are the weathered bedrock peeking through the melt sheet. PostIsidis volcanic flows relatively enriched in high-Ca pyroxene could well be comparable to the early phases of volcanism that follow the basin formation (equivalent to Lacus Veris and Autumni) in the Orientale Basin. With time, the volcanic flows from Syrtis Major evolve to dominate the surface materials south and east of the Nili Fossae region, and flow down off the plateau to the edge of the floor of the Isidis basin to the south [Hiesinger and Head, 2004] interfingering with the Vastitas Borealis Formation that has filled the Isidis Basin [e.g., Ivanov and Head, 2003]. Degradation and erosion can expose breccia dikes and substrate [e.g., Head and Mustard, 2006] underlying the impact melt layers.

[32] As described in the introduction, a number of plausible hypotheses have been presented to explain the unusual concentration of olivine-rich outcrops at the surface of Mars. Hoefen et al. [2003] advocate that the olivine is hosted in crustal rocks, perhaps formed in an igneous intrusive complex, that are exposed by the Isidis basinforming event. On the basis of these new OMEGA, HRSC, and other imaging data, and supported by the observations of Hamilton and Christensen [2005] and Mangold et al. [2007], the olivine-rich outcrops are clearly a meters- to tens of meters-thick rock unit that rests on top of Noachian crust. There is no evidence of olivine-enriched lithologies exposed in the walls of graben and fractures, nor in impact crater ejecta, floor deposits, or walls that would support a crustal origin for the olivine.

[33] Hamilton and Christensen [2005] favor a primarily volcanic origin for these deposits via subaerial eruption of olivine-rich basalts. They cite as supporting evidence the lack of evidence for intrusive relationships, the presence of parallel and sub-parallel lineaments at MOC resolution interpreted to be layers, and presence of geomorphic features consistent with flows. Impact melt sheets can express layerlike structures due to cooling fractures and jointing [Grieve, 1975]. Hamilton and Christensen [2005] conclude that these deposits were in place prior to the Isidis basinforming event because (1) the olivine-rich deposits are cut by fractures and graben contemporaneous with or post-dating Isidis, (2) there is a lack of olivine outcrops in the fracture walls, and (3) there is a large elevation encompassed by the olivine deposits $(0$ to $-3100 \mathrm{~m})$. They propose the distribution of olivine-rich flows across this elevation range was a result of post-Isidis tectonic modification of a surface that was presumably horizontal or gently sloped prior to the impact. Left unexplained is how the stratigraphy, textures, and morphology of the flows were preserved during the violent events that created the Isidis basin.

[34] The impact melt hypothesis described here accommodates many of the inconsistencies that arise in the alternative hypotheses. Impact melt generated by the Isidis basin-forming event would line the cavity of the basin and be concentrated between the inner peak ring area and the transient crater rim. We interpret the olivine-rich outcrops on the southern rim of Isidis and apparently beneath the Hesperian and younger cover on the Isidis floor [Tornabene et al., 2006] to be additional exposed remnants of impact melt. Because impact melt commonly contains abundant clasts and breccia materials, it rapidly cools resulting in a layer of rock that drapes preexisting topography. This results in local high spots emerging through the draping and cooling melt sheet. This phenomenon (that the time constant to cool the melt be shorter than the capacity of the melt to drain efficiently to all low-standing regions) results in a melt deposit that regionally covers a large topographic range and locally settles into lows but does not completely settle into an equipotential surface at the bottom of the newly formed basin. The Maunder Formation, interpreted to be impact melt in the Orientale Basin, illustrates this topographic and areal distribution [e.g., Head, 1974]. Faulting related to the adjustment of Isidis to loading and flexure from basin filling [Wichman and Schultz, 1989] created the fractures and graben that now cross the terrain, while extensive erosion in the Nili Fossae region has removed some of the impact basin deposits, revealing the altered Noachian basement. As part of this erosion process, extensive olivine-rich dune fields were created in the region [Hamilton and Christensen, 2005; Mangold et al., 2007] near outcrop remnants of the olivine-rich melt that are observed across the full topographic range of olivine exposures.

\section{Conclusions}

[35] The Nili Fossae region exhibits a complex geology that provides insight into processes operating during the early history of Mars. A critical aspect for understanding these processes is the setting of Nili Fossae within the northwestern quadrant of the Isidis impact basin. The excellent exposure of bedrock outcrops through portions of this region permit direct association of mineralogy and/or lithology, and morphology. OMEGA mineralogic information combined with high-resolution imaging in this region demonstrates the following: (1) Olivine-dominated outcrops are clearly associated with a meters- to tens of meters-thick cap unit. Where the unit is still intact, it exhibits a pitted/ textured surface that has been locally degraded to yardanglike surface morphologies and dunes. Because this unit rests on and is cut by structural and tectonic elements of the Isidis Basin we interpret the age of the unit to be associated with the Noachian Isidis Impact basin-forming event. (2) Phyllosilicate-rich outcrops display a knobby, 
degraded morphology with abundant linear ridges and stratigraphic relationships clearly demonstrate that these outcrops rest beneath the cap unit. We interpret the distinctive network-like ridge morphology to be the surface manifestations of impact breccia dikes. The relative stratigraphic position beneath the largely unaltered cap unit and broad geographic distribution [Mangold et al., 2007] indicate that the phyllosilicate alteration was a regional event that occurred largely prior to the Isidis basin-forming event.

[36] A number of lines of evidence lead us to conclude that the olivine-rich cap unit represents an impact melt deposit formed during the Isidis basin-forming event. The cap unit rests on Noachian-aged altered crust and its morphology suggests emplacement as a viscous and fluid material. The unit occurs across a large range of elevations and in a geographic position that is analogous to large impact melt deposits observed in the Orientale basin on the Moon. The Isidis event would have generated large quantities of impact melt and, given the extremely thin crust beneath Isidis, the melted material is likely to have melted the more mafic lower crust and/or upper mantle. Thus an important implication of this hypothesis is that the Nili Fossae region contains, at the surface, Noachian-aged impact melt generated from the lower crust and/or upper mantle.

[37] Regardless of the specific interpretation that the cap unit represents impact melt, the stratigraphic relationships revealed in the Nili Fossae region clearly indicate that a large region of the crust had undergone extensive alteration by the time of the Isidis impact event (Late Noachian). The nature of the alteration (Fe-rich smectite clay) requires conditions (abundant water, moderate temperatures, and neutral to basic acidity) that are incompatible with the presence of olivine: olivine would quickly weather and alter under these same conditions. Thus prior to the Late Noachian at least the shallow crust in this region supported and water-rich alteration environment, though we cannot yet definitively determine the specific time at which, nor duration over which, this alteration occurred. Since the time of the Isidis impact, however, conditions suitable for phyllosilicate formation have not occurred at the surface or in the shallow crust in the Nili Fossae region.

[38] Acknowledgments. Support from the NASA Planetary Geology and Geophysics Program from the NASA Goddard Space Flight Center is gratefully acknowledged (J.F.M., J.W.H.). J.F.M. also acknowledges a contract from the Jet Propulsion Laboratory to participate on the OMEGA Team as a Liaison Member from the CRISM Team, and J.W.H. acknowledges support from a contract from the Jet Proposal Laboratory for participation in the Mars Express High-Resolution Stereo Camera (HRSC).

\section{References}

Adams, J. B. (1974), Visible and near-infrared diffuse reflectance: Spectra of pyroxenes as applied to remote sensing of solid objects in the solar system, J. Geophys. Res., 79, 4829-4836.

Bandfield, J., V. E. Hamilton, and P. Christensen (2000), A global view of Martian surface composition from MGS-TES, Science, 287, 1626-1630. Bibring, J.-P., et al. (1989), Results from the ISM experiment, Nature, 341, $591-592$.

Bibring, J.-P., et al. (2004), OMEGA: Observatoire pour la Minéralogie, l'Eau, les Glaces et l'Activité, in Mars Express: The Scientific Payload, edited by A. Wilson, Eur. Space Agency Spec. Publ., ESA-1240, 37-49. Bibring, J.-P., et al. (2005), Mars surface diversity as revealed by the OMEGA/Mars Express observations, Science, 307, 1576-1581.

Bibring, J.-P., et al. (2006), Global mineralogical and aqueous Mars history derived from OMEGA/Mars Express data, Science, 312, 400-404.
Bratt, S. R., S. C. Solomon, and J. W. Head (1985), The evolution of impact basins: Cooling, subsidence, and thermal stress, J. Geophys. Res., 90, $12,415-12,433$.

Burns, R. G. (1993), Mineralogic Applications of Crystal Field Theory, 2nd ed., 551 pp., Cambridge Univ. Press, Cambridge, U. K.

Clark, R. N. (1999), Spectroscopy of rocks and minerals and principles of spectroscopy, in Remote Sensing for the Earth Sciences, Manual of Remote Sensing, 3rd ed., vol. 3, edited by A. Rencz, chap. 1, pp. 3-58, John Wiley, New York.

Cloutis, E. A., and M. J. Gaffey (1991), Pyroxene spectroscopy revisited: Spectral-compositional correlations and relationship to geothermometry, J. Geophys. Res., 96, 22,809-22,826.

Comer, R. P., S. C. Solomon, and J. W. Head (1985), Mars: Thickness of the lithosphere from the tectonic response to volcanic loads, Rev. Geophys. 23, 61-92.

Dressler, B. O., and W. U. Reimold (2001), Terrestrial impact melt rocks and glasses, Earth Sci. Rev., 56, 205-284.

Elkins-Tanton, L. T., P. C. Hess, and E. M. Parmentier (2005), Possible formation of ancient crust on Mars through magma ocean processes, J. Geophys. Res., 110, E12S01, doi:10.1029/2005JE002480.

Gendrin, A., et al. (2005), Sulfates in Martian layered terrains: The OMEGA/Mars Express view, Science, 307, 1587-1591.

Greeley, R., and J. E. Guest (1987), Geological map of the eastern equatorial region of Mars, U.S. Geol. Surv. Misc. Invest. Ser., Map I-1802-B

Grieve, R. A. F. (1975), Petrology and chemistry of impact melt at Mistastin Lake Crater, Labrador, Geol. Soc. Am. Bull., 86, 1617-1629.

Grieve, R. A. F. (1978), The melt rocks at Brent crater, Ontario, Canada, Lunar Planet. Sci., IX, 2579-2608.

Grieve, R. A. F., and M. J. Cintala (1992), An analysis of differential impact melt-crater scaling and implications for the terrestrial impact record, Meteoritics, 27, 526-538.

Grieve, R. A. F., and D. Stoffler (1991), The Sudbury structure: Controversial or misunderstood?, J. Geophys. Res., 96, 22,753-22,764.

Grieve, R. A. F., M. R. Dence, and P. B. Robertson (1977) Cratering processes: As interpreted from the occurrence of impact melts, in Impact and Explosion Cratering, edited by D. J. Roddy, R. O. Pepin, and R. B. Merril, pp. 791-814, Pergamon, New York

Grizzaffi, P., and P. H. Schultz (1989), Isidis basin: Site of ancient volatilerich debris layer, Icarus, 77, 358-381.

Hamilton, V. E., and P. R. Christensen (2005), Evidence for extensive, olivine-rich bedrock on Mars, Geology, 33, 433-436.

Hamilton, V. E., P. R. Christensen, H. Y. McSween Jr., and J. L. Bandfield (2003), Searching for the source regions of Martian meteorites using MGS TES: Integrating Martian meteorites into the global distribution of igneous materials on Mars, Meteorit. Planet. Sci., 38, 871885 .

Head, J. W. (1974), Orientale multi-ringed basin interior and implications for the petrogenesis of lunar highland samples, Moon, 11, 327-356.

Head, J. W. (1977), Origin of outer rings in lunar multi-ringed basins: Evidence from morphology and ring spacing, in Impact and Explosion Cratering, edited by D. J. Roddy, R. O. Pepin, and R. B. Merril, pp. 563-573, Pergamon, New York.

Head, J. W., and J. F. Mustard (2006), Breccia dikes in impact craters on Mars: Erosion and exposure on the floor of a $75-\mathrm{km}$ diameter crater at the dichotomy boundary, Meteorit. Planet. Sci., 41, 1675-1690.

Head, J. W., S. L. Murchie, J. F. Mustard, C. M. Pieters, G. Neukum, A. McEwen, R. Greeley, E. Nagel, and M. Belton (1993), Lunar impact basins: New data for the western limb and far side (Orientale and South Pole-Aitken Basins) from the first Galileo flyby, J. Geophys. Res., 98 , $17,149-17,181$

Head, J. W., III, M. A. Kreslavsky, and S. Pratt (2002), Northern lowlands of Mars: Evidence for widespread volcanic flooding and tectonic deformation in the Hesperian Period, J. Geophys. Res., 107(E1), 5003, doi:10.1029/2000JE001445

Hiesinger, H., and J. W. Head III (2004), The Syrtis Major volcanic province, Mars: Synthesis from Mars Global Surveyor data, J. Geophys. Res., 109, E01004, doi:10.1029/2003JE002143.

Hoefen, T. M., R. N. Clark, J. L. Bandfield, M. D. Smith, J. C. Pearl, and P. R. Christensen (2003), Discovery of olivine in the Nili Fossae region of Mars, Science, 302, 627-630.

Howard, K. A., D. E. Wilhelms, and D. H. Scott (1974), Lunar basins formation and highland stratigraphy, Rev. Geophys., 12, 309-327.

Ivanov, M. A., and J. W. Head III (2003), Syrtis Major and Isidis Basin contact: Morphological and topographic characteristics of Syrtis Major lava flows and material of the Vastitas Borealis Formation, J. Geophys Res., 108(E6), 5063, doi:10.1029/2002JE001994.

Mangold, N., et al. (2007), Mineralogy of the Nili Fossae region with OMEGA/Mars Express data: 2. Aqueous alteration of the crust, J. Geophys. Res., doi:10.1029/2006JE002835, in press. 
Masaitis, V. L. (1994), Impactites from Popigai crater, in Large Meteorite Impacts and Planetary Evolution, edited by B. O. Dressler et al., Spec. Pap. Geol. Soc. Am., 293, 153-162.

McCauley, J. (1977), Orientale and Caloris, Phys. Earth Planet. Inter, 15, $220-250$.

McSween, H. Y., Jr., T. L. Grove, and M. B. Wyatt (2003), Constraints on the composition and petrogenesis of the Martian crust, J. Geophys. Res., 108(E12), 5135, doi:10.1029/2003JE002175.

Meyer, J. D., and M. J. Grolier (1977), Geologic map of the Syrtis Major quadrangle of Mars, U.S. Geol. Surv. Misc. Invest Ser, Map I-995 (MC-13).

Milliken, R. E., and J. F. Mustard (2005), Quantifying absolute water content of minerals using near-infrared reflectance spectroscopy, J. Geophys. Res., 110, E12001, doi:10.1029/2005JE002534.

Mustard, J. F., and J. M. Sunshine (1995), Seeing through the dust on Mars: Links between the SNC meteorites and heterogeneity on the surface of the Red Planet, Science, 267, 1623-1626.

Mustard, J. F., S. L. Murchie, S. Erard, and J. M. Sunshine (1997), In situ compositions of Martian volcanics: Implications for the mantle, J. Geophys. Res., 102, 25,605-25,615.

Mustard, J. F., et al. (2004), Global spectral and compositional diversity of Mars: A test of CRISM global mapping with Mars Express OMEGA data, Eos Trans. AGU, 85(47), Fall Meet. Suppl, Abstract P24A-07.

Mustard, J. F., F. Poulet, A. Gendrin, N. Mangold, J.-P. Bibring, Y. Langevin, B. Gondet, G. Bellucci, F. Altieri, and the OMEGA Science Team (2005), Olivine and pyroxene diversity in the crust of Mars, Science, 307, 15941597.

Neumann, G. A., M. T. Zuber, M. A. Wieczorek, P. J. McGovern, F. G. Lemoine, and D. E. Smith (2004), Crustal structure of Mars from gravity and topography, J. Geophys. Res., 109, E08002, doi:10.1029/2004JE002262.

Pelkey, S. M., et al. (2007), CRISM multispectral summary products: Parameterizing mineral diversity on Mars from reflectance, J. Geophys. Res., 112, E08S14, doi:10.1029/2006JE002831.

Pieters, C. M., , and P. A. J. Englert (Eds.) (1993), Remote Geochemical Analysis: Elemental and Mineralogical Composition, Cambridge Univ. Press, New York.

Pieters, C. M., et al. (1993), Crustal diversity of the Moon: Compositional analyses of Galileo solid state imaging data, J. Geophys. Res., 98 , $17,127-17,148$

Pope, K. O., S. W. Kieffer, and D. E. Ames (2006), Impact melt sheet formation on Mars and its implication for hydrothermal systems and exobiology, Icarus, 183, 1-9.

Poulet, F., J.-P. Bibring, J. F. Mustard, A. Gendrin, N. Mangold, Y. Langevin, R. E. Arvidson, B. Gondet, G. Gomez, and the Omega Science Team
(2005), Phyllosilicates on Mars and implications for the early Mars history, Nature, 438, 623-627, doi:10.1038/nature04274.

Schaber, G. G. (1982), Syrtis major: A low-relief volcanic shield, J. Geophys. Res., 87, 9852-9866.

Schultz, R. A., and H. V. Frey (1990), A new survey of multiring impact basins on Mars, J. Geophys. Res., 95, 14,175-14,189.

Simonds, C. H., R. J. Floran, P. E. McGee, W. C. Phinney, and J. L. Warner (1978), Petrogenesis of melt rocks, Manicouagan impact structure, Quebec, J. Geophys. Res., 83, 2773-2788.

Solomon, S. C., and J. W. Head (1979), Vertical movement in mare basins: Relation to mare emplacement, basin tectonics, and lunar thermal history, J. Geophys. Res., 84, 1667-1682.

Solomon, S. C., and J. W. Head (1980), Lunar mascon basins: Lava filling, tectonics, and evolution of the lithosphere, Rev. Geophys., 18, 107-141. Spudis, P. D., B. R. Hawke, and P. G. Lucey (1984), Composition of Orientale basin deposits and implications for the lunar basin-forming process, Proc. Lunar Planet. Sci. Conf. 15th, Part 1, J. Geophys. Res., 89, suppl., C197-C210.

Tanaka, K. L., J. A. Skinner Jr., and T. M. Hare (2005), Geologic map of the Northern Plains of Mars, U.S. Geol. Surv. Sci. Invest. Ser, Map 2888.

Tornabene, L. L., J. E. Moersch, H. Y. McSween Jr., V. E. Hamilton, J. L. Piatek, K. A. Milam, and P. R. Christensen (2006), The subsurface geology of Mars: Remote sensing of impact craters using THEMIS, TES, MOC and MOLA, Lunar Planet. Sci., XXXVII, Abstract 1739.

Wichman, R. W., and P. H. Schultz (1989), Sequence and mechanisms of deformation around the Hellas and Isidis impact basins on Mars, J. Geophys. Res., 94, 17,333-17,357.

Wilhelms, D. E. (1973), Comparison of Martian and lunar multiringed circular impact basins, J. Geophys. Res., 78, 4084-4095.

Wilhelms, D. E. (1987), The geology of the Moon, U.S. Geol. Surv. Prof., 1348

J.-P. Bibring, Y. Langevin, and F. Poulet, Institut d'Astrophysique Spatiale, CNRS/Université Paris Sud, Bâtiment 120, F-91405 Orsay, France.

C. I. Fassett, J. W. Head, J. F. Mustard, and S. M. Pelkey, Department of Geological Sciences, Brown University, Box 1846, Providence, RI 02912, USA. (john_mustard@brown.edu)

N. Mangold, Laboratoire IDES, UMR8148 CNRS and Université ParisSud, Bâtiment 509, F-91405 Orsay Cedex, France.

G. Neukum, Institut für Geologische Wissenschaften, Freie Universität Berlin, D-12489 Berlin, Germany. 